\title{
ASSESSing Graduate ATtributes as Described by CEAB: AN EXPLORATORY STUDY IN A FirST YEAR DESIGN COURSE
}

\author{
Daniel Dupuis ${ }^{1}$, and Christian St-Pierre ${ }^{2}$ \\ ${ }^{1}$ Chemical Engineering Department, Université Laval, ${ }^{2}$ Faculty of sciences and engineering, Université Laval \\ Daniel.Dupuis@fsg.ulaval.ca, Christian.St-Pierre@fsg.ulaval.ca
}

\begin{abstract}
During the fall of 2012, an experimental validation of the integration and assessment of six out of the twelve CEAB's graduate attributes has been performed in the first year design course "GSC-1000 Méthodologie de design en ingénierie".

Taking advantage of the authenticity of the learning context, and focusing on the necessity to develop just as authentic assessment tools, scoring rubrics have been extensively used in the assessment process. Automated data analysis algorithms have been embedded in the engineering faculty's Intranet in order to facilitate the transition from the scoring rubric to a set of efficiently interpretable diagrams, supporting the assessor in its feedback delivery to learners.

Results suggest that, at the beginning of the program, the study cohort presents an overall level of performance slightly below expectations in attributes 3.1.4 - Design, 3.1.6 - Individual and team work, and 3.1.9 - Impact of engineering on society and the environment, as expected for attribute 3.1.12 - Life-long learning, slightly above expectations for attribute 3.1.11 - Economics and project management, and dramatically below acceptability for attribute 3.1.7 - Communication skills.
\end{abstract}

Keywords: Graduate attributes, project-based learning, authentic assessment, higher education.

\section{INTRODUCTION}

Undergraduate engineering programs all across Canada have to meet or exceed educational standards as prescribed by the Canadian Engineering Accreditation Board (CEAB) [1]. By 2015, these standards will include twelve attributes that graduates will have to possess by the end of their studies. Attributes are: 3.1.1 - A knowledge base for engineering, 3.1.2 - Problem analysis, 3.1.3. Investigation, 3.1.4. - Design, 3.1.5. - Use of engineering tools, 3.1.6 - Individual and team work, 3.1.7 Communication skills, 3.1.8 - Professionalism, 3.1.9 Impact of engineering on society and the environment,
3.1.10 - Ethics and equity, 3.1.11 - Economics and project management, and 3.1.12 - Life-long learning.

As clearly underlined by Frank [2], CEAB's graduate attributes are closely related to requirements from other countries in the Washington Accord. Strong similarities with the US, UK and Australian procedures ensure that the Canadian system is aligned with the requirements of other engineering accreditation procedures in other jurisdictions.

Moreover, it is believed that the shift in CEAB's accreditation procedure will also help fixing the inadequate skills often observed by employers in young engineers [3]. At the same time, it will also help preparing new graduates for the important challenges waiting for them in a world strongly influenced by the concept of "global engineering".

Although these new standards in the accreditation procedure do not imply that Canadian engineering programs need to be competency-based wall-to-wall, it is hard not to recognize that some graduate attributes clearly refer to competencies (which is the case for communication skills, teamwork and life-long learning, just to mention a few).

In such a context, using authentic assessment strategies to evaluate the professional development of the student (or should we say "learner"), as he proceeds through his learning, becomes inevitable. But as pinpointed by Herrington [4] as early as 2006, authentic assessment is a major issue in higher education. Regardless whether the root cause of the problem is related to institutional or pedagogical impediment, it seems obvious that in an environment where technologybased learning becomes more and more popular, and where virtual classrooms tend to grow bigger and bigger, assessment becomes a huge challenge, especially when it comes to meet educational standards as those prescribed by the CEAB.

Considering that most (if not all) faculties of engineering across Canada are experiencing similar challenges, we hope that sharing these observations will be helpful for the engineering education community. 
It is with this in mind that an exploratory study was conducted in a first year design course involving students from eleven different engineering programs at Université Laval, Québec, and focusing on the development of six out of the twelve graduate attributes. This paper aims at presenting preliminary results for this study.

\section{METHODOLOGY}

As most Canadian universities offering engineering programs, Université Laval started up, a few years ago, the important revision based on CEAB's new accreditation standards. In the process, the twelve graduate attributes have been subdivided into components, in order to make their assessment easier and more representative. Appendix A shows the detailed list of graduate attributes and corresponding components.

Components have been further divided into performance criteria, which were used in the elaboration of scoring rubrics. Descriptors of the scoring rubric were defined so that the evaluator can observe the actual performance of the learner according to each criterion, and then grade it on a four level scale (graded "Exceeds expectations", "Meets expectations", "Marginal" and "Below expectations"). As an example of a typical scoring rubric, appendix $\mathrm{B}$ shows the rubric used for assessing attribute 3.1.4 - Design.

Scoring rubrics describe the performance or behavior that we wish our graduate to be able to exhibit at the end of their 4-year program. In order to make the assessment authentic, we make sure that the learner is familiar with the scoring rubrics beforehand, and that the same rubrics will be used throughout the entire program, whenever the assessment of a graduate attributes is required.

One of the rubric's main advantages is that it allows us to follow the learner's evolution along his development path, and throughout the program. Consequently, it implies that before being used in a summative way to assess the graduate attributes development at the end of the program, scoring rubrics will be used as a nonterminal, formative assessment tool.

It is the case for all assessment opportunities in the design course considered for the purpose of this study, GSC-1000.

\subsection{Learning Context}

GSC-1000 is a project-based course where students, divided in teams of four to six members, develop design abilities, as well as teamwork and communication skills, while realizing an engineering design project.

At the beginning of the term, teams are asked to identify a topical issue that prevails (locally or globally) on the planet and that can be resolved by the design of an engineering product. Throughout the semester, they have to follow a rigorous design methodology that brings them to come up with an optimal solution after fifteen weeks.

Through their project, students are also introduced to the basics of project management and sustainable development.

For the purpose of this study, 160 students divided into 29 teams were initially considered. Students who were not enrolled in an engineering program and students who quit the course before the end of the term were then removed from the cohort, leaving 134 students for the study.

An important characteristic of GSC-1000 relies in the extensive use of techno pedagogical tools and strategies. Whether it is for the distance version of the course (which is followed by approximately $20 \%$ of our students) or the traditional classroom-based version, all students have constant asynchronous access to the educational content through the course's web site. The content takes various forms, including interactive case-studies, instructional video-clips, PDF documents, and narrated PowerPoint presentations.

By nature, GSC-1000 seems to be a well-suited environment for developing six out of the twelve graduate attributes prescribed by the CEAB. These attributes, namely 3.1.4 - Design, 3.1.6 - Individual and team work, 3.1.7 - Communication skills, 3.1.9 - Impact of engineering on society and the environment, 3.1.11 Economics and project management, and 3.1.12 - Lifelong learning, are assessed, in parts or as a whole through a series of deliverables spread out over the semester.

\subsection{Deliverables}

Table 1 shows the list of deliverables associated with the graduate attribute's components it relates to (as listed in appendix A). Most deliverables fall either as checkpoints in the general progress of the design process, as traditional project management items, or as punctual elements showing the end result of the project.

In a first case, they often take the form of tables, figures, diagrams, or notes, which usually fit on a twopager. Such deliverables show the ability of the learners to use a structured approach for design purposes, and to analyze the impacts of their decisions and recommendations on society and the environment.

Weekly deliverables associated with project or team management include meeting agenda, meeting minutes, peer-to-peer evaluations, and schedule and tasks management. These elements, observed on a periodical basis all along the term, lead to the assessment of components related to teamwork and project management attributes.

Communication skills are assessed through a final technical report and an oral presentation, both concerning the optimal solution recommended at the end of the term. 
Finally, the ability for the learner to auto evaluate its own development regarding the attributes assessed in the course is validated at the end of the term, through a selfreflection exercise. Reflections are documented in the student's personal webfolio [5].

Table 1: Deliverables leading to attributes assessment.

\begin{tabular}{|l|c|}
\hline \multicolumn{1}{|c|}{ Deliverables } & Component \\
\hline - Design process milestones & 3.1 .4 .1 \\
(project proposition, & 3.1 .4 .2 \\
specifications, functional & 3.1 .4 .3 \\
analysis, concepts generation, & 3.1 .4 .5 \\
feasibility analysis, etc.) & 3.1 .9 .1 \\
\hline - Weekly meetings agenda and & 3.1 .6 .1 \\
- minutes & \\
- Peer assessment of abilities to & 3.1 .6 .2 \\
\hline - Fork within a team & \\
\hline - Final oral presentation & 3.1 .7 .1 \\
\hline - Schedule and tasks & 3.1 .7 .2 \\
\hline - Webfolio & 3.1 .11 .2 \\
\hline
\end{tabular}

\subsection{Data Analysis}

By superimposing scoring rubrics to the corresponding deliverables, we can assess the performance level of the learners with regards to each performance criterion associated with the graduate attributes components.

It is to be noted that all assessments (but 3.1.6.2 and 3.1.12.1) translate team performances (rather than individual performances within the team). Therefore, most of the information given to the learner by the assessment process, relate to the outcomes of the team's collective learning.

Moreover, since each graduate attribute is subdivided into components and performance criteria, its overall level of performance will be that of the weakest criterion on the scoring rubric.

By analogy, let's pretend the attribute refers to the ability of a pilot to land a plane, and that this ability is described by a five steps procedure (with each step corresponding to a performance criteria). In this case, failing in any of the five steps will result in an unsuccessful landing (therefore, the relevance of considering the weakest criterion as a bottleneck, instead of averaging all criteria).

In order to get a global picture of the cohort performances, individual results are further averaged.

\section{RESULTS}

Considering the important number of students enrolled in the course, it is obvious that our intention is not to present individual results for all teams, but rather to showcase examples of teams' and cohort's performances.

This section presents typical radar diagrams that were obtained with the data collected at the end of the experimentation.

On all diagrams, the dotted black line defines the expected level of performance (at the end of the 4-year program), whereas the plain black line represents the actual level of performance. The green zone above the dotted line defines the "excellence", whereas the yellow zone refers to performance levels ranging from "marginal" to "expected". Anything falling in the red zone is considered as being "below expectations". Radial axes of the diagram represent each of the six graduates attributes assessed in the course.

The first three diagrams present typical data for teams that have shown "above expectations" (Fig.1), "as expected" (Fig.2) and "below expectations" (Fig.3) levels of performance for most of the attributes. Figure 4 shows the average levels of performance when the entire cohort is considered.

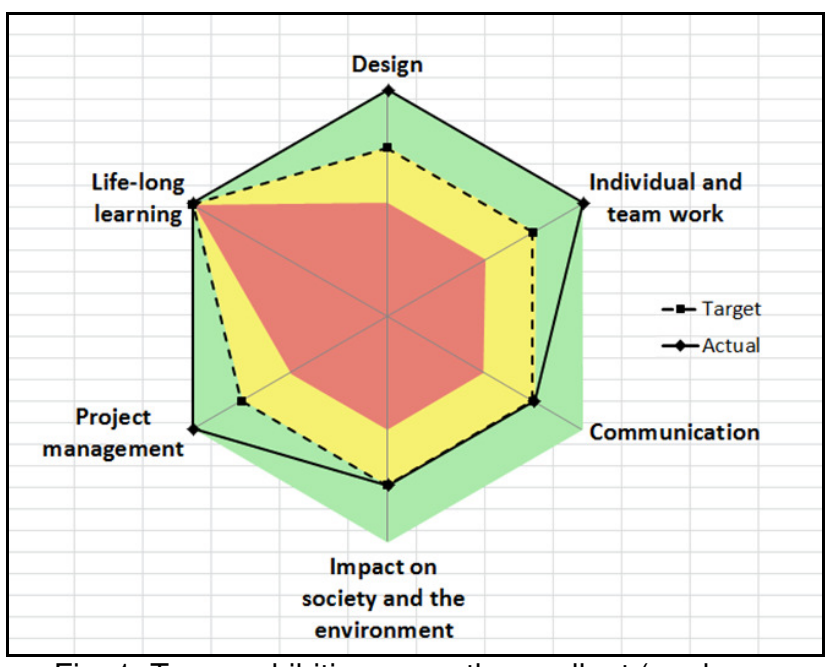

Fig. 1. Team exhibiting a mostly excellent (or above expectations) level of performance. 


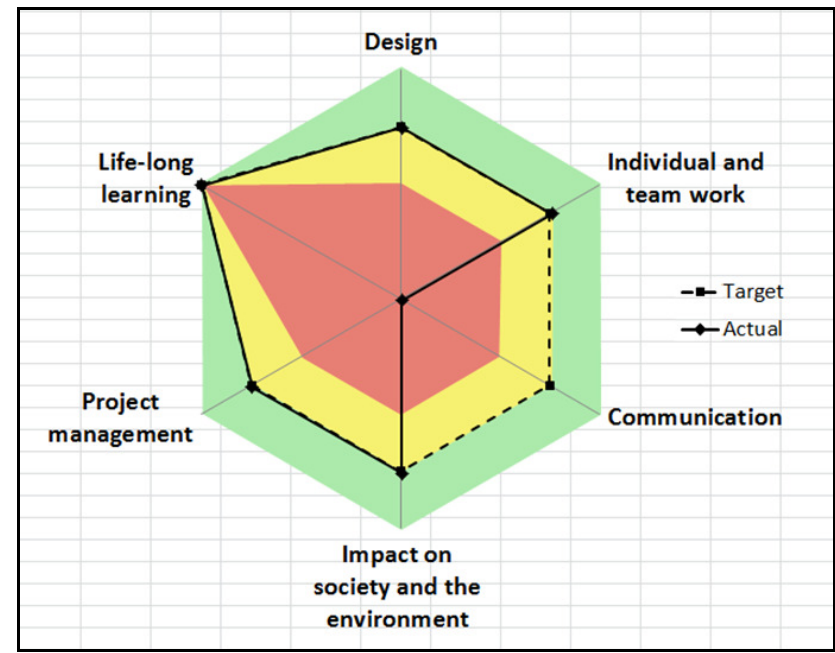

Fig. 2. Team exhibiting a satisfying level of performance in most attributes.

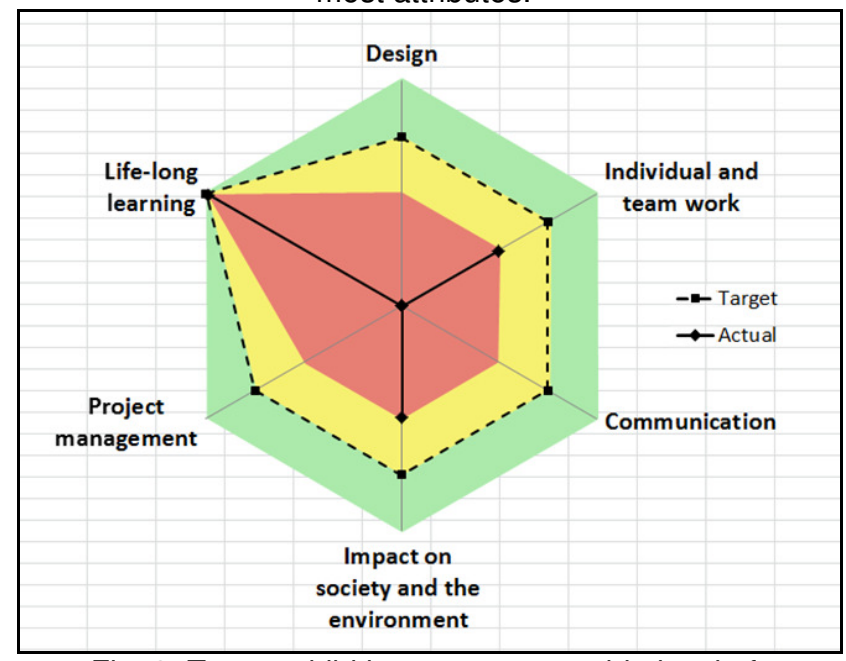

Fig. 3. Team exhibiting an unacceptable level of performance in most attributes.

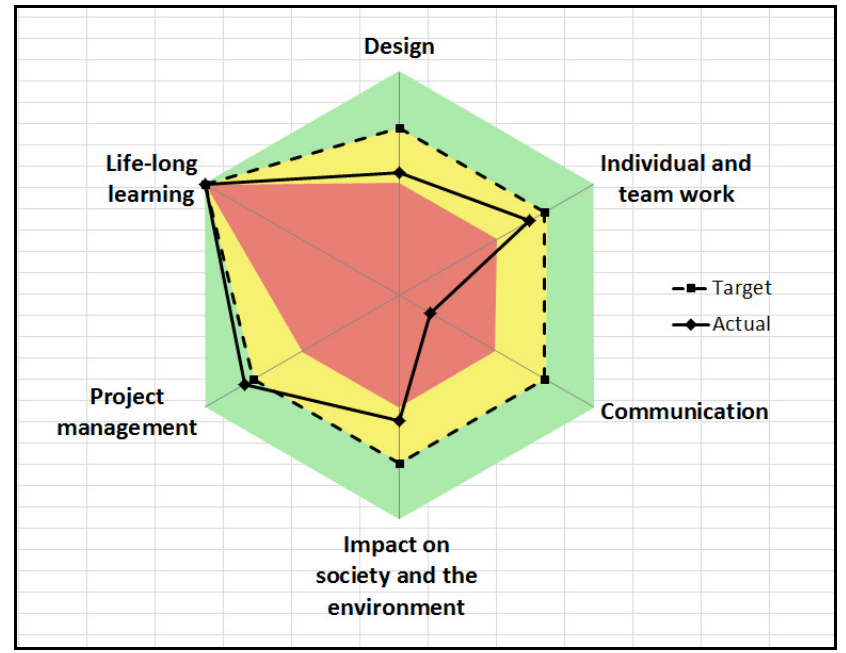

Fig. 4. Average levels of performances for the entire cohort (134 students).

\section{DISCUSSION}

\subsection{An Efficient Feedback Tool}

Figure 1 to Fig. 3 show examples of diagrams that will assist the teacher when it comes to delivering formative feedback to the learners. Presented that way, it is very easy for both parties to visualize individual strengths and weaknesses (collective strengths and weaknesses in this case since GSC-1000 assesses team performances).

The diagrams make it easier for the teacher to rapidly identify teams that experience difficulties, and efficiently prepare his mentoring interventions on specific topics.

Combined with the corresponding detailed scoring rubrics, this graphical representation of the learner's level of performance becomes a powerful tool when it comes to identifying its individual educational needs, as will be eventually prescribed by attribute 3.1.12.

To make it an efficient feedback tool, data analysis and diagrams plotting need to be computerized so that the only responsibility of the assessor (other, of course, than providing feedback to students), is to capture data for processing.

Processing algorithms are already built-in into the engineering faculty's Intranet. We are currently planning the integration of additional features for improving graphical representations and for making easier navigating through the results.

\subsection{Assessing the Entire Cohort}

Figure 4 shows that, generally speaking, the cohort is below expectations when considering attributes 3.1.4 Design, 3.1.6 - Individual and team work and 3.1.9 Impact of engineering on society and the environment. Giving the non-terminal, formative nature of the assessment process, and the fact that this snapshot of the cohort's level of performance represents the beginning of the journey (and not the end), this observation is not that concerning.

What is preoccupying, though, is the dramatically lowlevel of performance observed for attribute 3.1.7 Communication skills, which is mostly influenced by the poor writing skills of our students (not shown here, but clearly observable in the raw data).

As for the assessment of project management skills, let's recall that the only component that was considered at this point was the ability to keep updated a project schedule (both budget and risk management are not assessed in the course). Considering the cohort's level of performance, the teams were mostly successful at doing so. From the students' point of view though, the necessity of keeping their project's schedule updated on a weekly 
basis, was very time-consuming and might have distracted them from focusing on other tasks (like writing good reports).

Regarding attribute 3.1.12 - Life-long learning, the only requirement for it to be fulfilled (in the scope of the course) was that self-reflections on the learner's development needed to be documented in their personal webfolio (regardless the content). Since the webfolio was a mandatory appendix of the final report, it is no surprise that all students achieved the highest level of performance for 3.1.12 - Life-long learning.

\section{CONCLUSION AND RECOMMENDATIONS}

This exploratory study falls in with the revision of CEAB's accreditation procedures, regarding the integration of the twelve specific attributes that graduates of a program will have to possess.

A first-year project-based design course has been identified as a test bench for validating the integration and assessment of six out of the twelve attributes.

Attributes' assessment has been performed using scoring rubrics, and results have been represented on radar diagrams for clarity and ease of interpretation.

In the light of this experimentation, recommendations have been made in order to facilitate the transition towards the next steps of the process.

\subsection{Recommendations}

5.1.1 Revisiting the List of Assessed Attributes. Attribute 3.1 .11 is only partially covered with the assessment process. Moreover, since it involves a weekly monitoring of the project schedule, the experience has suggested that this component is highly time-consuming (both for the learner and the assessor). Combined to the fact that results for attributes 3.1.11 were globally over the expected performance level for the entire cohort, it is recommended to remove it from the list, so that energies and efforts can be focused on other, more crucial elements.

For completely different reasons, it is also recommended to remove attribute 3.1 .9 from the list. This attribute, directed at the analysis of impacts of engineering on society and the environment, implies a better understanding of what engineers do in "real-life". The lack of experience of first-year students becomes a serious flaw in this context.

Regardless we consider Bloom's revised taxonomie [6] (which is generally well recognized in education), or an engineering-practice adaptation of Miller's pyramid as the one suggested by McCahan [7], the observation stands: Taxonomic levels of what we ask relative to this topic (in the scope of GSC-1000), is not high enough to make the 3.1.9 scoring rubric useable.

This is why we strongly recommend limiting the list of attributes assessed through GSC-1000, to 3.1.4, 3.1.6, 3.1.7 and 3.1.12.

5.1.2 Standardizing the Assessment Protocols. During the fall of 2012, 538 students were enrolled in GSC-1000. However, mostly due to a misunderstanding in the assessment protocols among the teaching team, only 134 students were eligible for the study. From this unfortunate situation, we learned a lot on how to standardize our assessment protocols, so that all of the data will be useable in the future.

Formatted spreadsheets will be prepared, in order to simplify the assessor's task when it comes to record data. Assessment procedures will be documented and dry-run sessions will be organized with all individuals involved in the assessment process. These opportunities to make common evaluations of typical deliverables should increase the uniformity and efficiency of the process.

\subsubsection{Continuous Improvement of Computerized} Tools. Regardless it is for the early detection of specific flaws within the project teams, or the follow-up of progressions on both an individual (team) and a collective (cohort) basis, computerized assessment tools have shown their great value in this study.

However, there is still room for improvement and a need to be steadily proactive, in order to make sure the assessment process is as painless as possible for the assessor, while being as clear as possible for the learner.

\section{Acknowledgements}

We would like to acknowledge the exceptional contribution of Hélène Servais, pedagogical counselor at the Faculty of sciences and engineering at Université Laval. Being the mastermind of this whole program revision exercise, Hélène's contribution extends far beyond the experimental study presented in this paper. Nonetheless, we would never have been able to achieve such satisfying results without her sound advices on the topic.

Our sincere appreciation also goes to Yvan Maciel and Philippe Cardou, both Professors in the Department of Mechanical Engineering at Université Laval, who played a crucial role in the elaboration of all scoring rubrics used in this study.

\section{References}

[1] Canadian Engineering Accreditation Board. "Accreditation Criteria and Procedures 2012", Available as of March 19, 2013 from 
http://www.engineerscanada.ca/files/w_Accreditation_Criter ia_Procedures_2012.pdf

[2] Brian Frank, "Development of Processes and Criteria for CEAB Graduate Attribute Assessment," in Proc. CDEN/C2E2 2009 Conf. (Hamilton, ON; 27-29 July 2009), 2009.

[3] Adrian Chan, and Jonathan Fishbein, "A Global Engineer for the Global Community," The Journal of Policy Engagement., vol. 1, no. 2, pp. 4-9, May 2009.

[4] Herrington, J. and Anthony Herrington, "Authentic Conditions for Authentic Assessment: Aligning Task and Assessment," in Critical Vision, Proc. of the $29^{\text {th }}$ HERDSA Annual Conf., Western Australia; 10-12 July 2006, pp. 146151.

[5] Service de placement de l'Université Laval, "Mon Webfolio ", Available as of April 29 $9^{\text {th }}, 2013$ from https://www.spla.ulaval.ca/webfolio/

[6] Lorin W. Anderson, David R. Kratwohl, Peter W. Airasian, Kathleen A. Cruikshank, Richard E. Mayer, Paul R. Pintrich, James Raths, and Merlin C. Wittrock, A Taxonomy for Learning, Teaching and Assessing: A Revision of Bloom's Taxonomy of Educational Objectives. New-York, NY: Addison Wesley Longman Inc., 2001, 352 pp. \{ISBN 321-08405-5\}

[7] Susan McCahan, and Lisa Romkey, "Beyond Bloom's: Useful Constructs for Developing Graduate Attribute Indicators," in Proc. $2^{\text {nd }}$ Annual CEEA Conf. (St.John's, NL; 6-8 June 2011), 2011.

\section{APPENDIX A: Graduate attributes and local components}

\begin{tabular}{|c|}
\hline 3.1.1 - A knowledge base for engineering \\
\hline 3.1.1.1 - Demonstrate competence in university level mathematics. \\
\hline $\begin{array}{l}\text { 3.1.1.2 - Demonstrate competence in university level natural } \\
\text { sciences and engineering. }\end{array}$ \\
\hline 3.1.2 - Problem analysis \\
\hline 3.1.2.1 - Identify the problem. \\
\hline $\begin{array}{l}\begin{array}{l}\text { 3.1.2.2 - Formulate the problem using hypotheses and } \\
\text { simplifications. }\end{array} \\
\end{array}$ \\
\hline 3.1.2.3 - Select and use analysis methods to solve the problem. \\
\hline 3.1.2.4 - Assess the validity of the solution and methods. \\
\hline 3.1.3 - Investigation \\
\hline 3.1.3.1 - Define the issue at hand. \\
\hline 3.1.3.2 - Plan the investigation approach. \\
\hline 3.1.3.3 - Apply research methods. \\
\hline $\begin{array}{l}\text { 3.1.3.4 - Analyze and interpret information and data, and reach } \\
\text { valid conclusions. }\end{array}$ \\
\hline 3.1.4 - Design \\
\hline 3.1.4.1 - Understand the mandate and define the problem. \\
\hline 3.1.4.2 - Generate several solution concepts. \\
\hline
\end{tabular}

3.1.4.3 - Select the best concept.

3.1.4.4 - Develop the best concept into a solution.

3.1.4.5 - Assess the selected solution

3.1.5 - Use of engineering tools

3.1.5.1 - Know the appropriate techniques, resources and engineering tools and select them according to needs.

3.1.5.2 - Properly use appropriate techniques, resources and engineering tools to carry out a particular task or project.

3.1.5.3 - Adapt or create techniques, resources and engineering tools according to the requirements of a task or project to be carried out.

3.1.6 - Individual and team work

3.1.6.1 - Organize and lead meetings.

3.1.6.2 -Encourage collaboration and manage interpersonal relations.

3.1.7 - Communication skills

3.1.7.1 - Make oral presentations.

3.1.7.2 - Write technical documents: Proposals, reports, design documentation and instructions.

3.1.8 - Professionalism

3.1.8.1 - Understand Québec's professional system.

3.1.8.2 - Differentiate between the basic notions related to the professional role and responsibility.

3.1.8.3 - Understand the engineering profession and interaction with partners.

3.1.9 - Impact of engineering on society and the environment

3.1.9.1 - Analyze the impacts of a project on society and the environment.

\subsubsection{0 - Ethics and equity}

3.1.10.1 - Recognize and clarify basic notions related to professional ethics.

3.1.10.2 - Analyze professional situations involving ethical issues. 3.1.10.3 - Address situations and make decisions.

3.1.11 - Economics and project management

3.1.11.1 - Conduct an economic analysis in the context of an engineering project subject to risk and change.

3.1.11.2 - Incorporate basic functions into the management of an engineering project subject to risk and change.

\subsubsection{2 - Life-long learning}

3.1.12.1 - During one's training, self-assess the development of personal and professional attributes defined by CEAB.

3.1.12.2 - Plan the development of one's skills.

\section{APPENDIX B: Example of Scoring Rubric: Attribute 3.1.4 - Design}

Appendix B shows and example of a typical scoring rubric, used in the assessment process. The example stands for attribute 3.1.4 - Design. Starting with the local components identified by the program advisory committee (first column on the left), it details the performance criteria (second column) and emphasizes the descriptors representing each of the performance level. 
Scoring Rubric: 3.1.4 - Design

\begin{tabular}{|c|c|c|c|c|c|}
\hline Component & Criteria/Indicators & Below Expectations & Marginal & Meets Expectations & Exceeds Expectations \\
\hline \multirow[t]{2}{*}{$\begin{array}{l}\text { 3.1.4.1 } \\
\text { Understand } \\
\text { the mandate } \\
\text { and define the } \\
\text { problem }\end{array}$} & $\begin{array}{l}\text { 3.1.4.1.1 } \\
\text { Identification } \\
\text { accuracy }\end{array}$ & $\begin{array}{l}\text { Is not able to define } \\
\text { the complex } \\
\text { engineering problem, } \\
\text { the needs of the } \\
\text { project initiator and/or } \\
\text { the problem's } \\
\text { constraints. }\end{array}$ & $\begin{array}{l}\text { Properly identifies, but } \\
\text { with a few deficiencies } \\
\text { or omissions, the } \\
\text { complex engineering } \\
\text { problem, the needs of } \\
\text { the project initiator } \\
\text { and the problem's } \\
\text { constraints. }\end{array}$ & $\begin{array}{l}\text { Clearly identifies the } \\
\text { complex } \\
\text { engineering } \\
\text { problem, the needs } \\
\text { of the project } \\
\text { initiator and the } \\
\text { problem's } \\
\text { constraints. }{ }^{1}\end{array}$ & $\begin{array}{l}\text { Very clearly identifies, } \\
\text { and in a comprehensive } \\
\text { manner, the complex } \\
\text { engineering problem, the } \\
\text { needs of the project } \\
\text { initiator and the } \\
\text { problem's constraints. }{ }^{1}\end{array}$ \\
\hline & $\begin{array}{l}\text { 3.1.4.1.2. } \\
\text { Problem } \\
\text { formulation }\end{array}$ & $\begin{array}{l}\text { Does not establish } \\
\text { specifications or omits } \\
\text { several key assessment } \\
\text { criteria. }\end{array}$ & $\begin{array}{l}\text { Establishes } \\
\text { specifications with a } \\
\text { minimum of details. } \\
\text { Selects most of the key } \\
\text { assessment criteria and } \\
\text { weighs them } \\
\text { appropriately. }\end{array}$ & $\begin{array}{l}\text { Establishes } \\
\text { sufficiently detailed } \\
\text { specifications. } \\
\text { Selects relevant } \\
\text { assessment criteria } \\
\text { and weighs them } \\
\text { appropriately. }\end{array}$ & $\begin{array}{l}\text { Establishes sufficiently } \\
\text { detailed specifications. } \\
\text { Wisely selects } \\
\text { assessment criteria and } \\
\text { weighs them } \\
\text { appropriately. }\end{array}$ \\
\hline \multirow[t]{2}{*}{$\begin{array}{l}3.1 .4 .2 \\
\text { Generate } \\
\text { several } \\
\text { solution } \\
\text { concepts }\end{array}$} & $\begin{array}{l}\text { 3.1.4.2.1 } \\
\text { Appropriateness of } \\
\text { concepts }\end{array}$ & $\begin{array}{l}\text { Generates concepts } \\
\text { that do not meet } \\
\text { specifications. }\end{array}$ & $\begin{array}{l}\text { Generates several } \\
\text { concepts meeting } \\
\text { specifications. }\end{array}$ & $\begin{array}{l}\text { Generates several } \\
\text { concepts meeting } \\
\text { specifications. }\end{array}$ & $\begin{array}{l}\text { Generates several } \\
\text { concepts meeting } \\
\text { specifications, including } \\
\text { some that may be } \\
\text { innovative. }\end{array}$ \\
\hline & $\begin{array}{l}\text { 3.1.4.2.2 } \\
\text { Use of knowledge, } \\
\text { techniques and } \\
\text { tools }\end{array}$ & $\begin{array}{l}\text { Does not properly use } \\
\text { knowledge, } \\
\text { calculations and } \\
\text { design techniques and } \\
\text { tools and shows very } \\
\text { little creativity, } \\
\text { judgment and ability } \\
\text { to synthesize } \\
\text { information to } \\
\text { generate concepts. }\end{array}$ & $\begin{array}{l}\text { Uses, to some small } \\
\text { extent, knowledge, } \\
\text { calculations and } \\
\text { design techniques and } \\
\text { tools and moderately } \\
\text { shows creativity, } \\
\text { judgment and ability } \\
\text { to synthesize } \\
\text { information to } \\
\text { generate concepts. }\end{array}$ & $\begin{array}{l}\text { Properly uses } \\
\text { knowledge, } \\
\text { calculations and } \\
\text { design techniques } \\
\text { and tools and shows } \\
\text { creativity, judgment } \\
\text { and ability to } \\
\text { synthesize } \\
\text { information to } \\
\text { generate concepts. }\end{array}$ & $\begin{array}{l}\text { Skillfully uses } \\
\text { knowledge, calculations } \\
\text { and design techniques } \\
\text { and tools and shows } \\
\text { considerable creativity, } \\
\text { judgment and ability to } \\
\text { synthesize information } \\
\text { to generate concepts. }\end{array}$ \\
\hline $\begin{array}{l}3.1 .4 .3 \\
\text { Select the best } \\
\text { concept }\end{array}$ & $\begin{array}{l}\text { 3.1.4.3.1 } \\
\text { Selection of the } \\
\text { best concept based } \\
\text { on assessment } \\
\text { criteria }\end{array}$ & $\begin{array}{l}\text { Does not use a rational } \\
\text { and objective } \\
\text { approach based on the } \\
\text { assessment criteria to } \\
\text { select the best concept. }\end{array}$ & $\begin{array}{l}\text { Selects the best } \\
\text { concept based on the } \\
\text { assessment criteria, } \\
\text { but by conducting an } \\
\text { analysis that lacks } \\
\text { rigour. }\end{array}$ & $\begin{array}{l}\text { Selects the best } \\
\text { concept in a rational } \\
\text { and objective } \\
\text { manner, rigorously } \\
\text { based on the } \\
\text { assessment criteria. }\end{array}$ & $\begin{array}{l}\text { Selects the best concept } \\
\text { in a rational, objective } \\
\text { and very precise manner, } \\
\text { rigorously based on the } \\
\text { assessment criteria. }\end{array}$ \\
\hline $\begin{array}{l}\text { 3.1.4.4 } \\
\text { Develop the } \\
\text { best concept } \\
\text { into a solution }\end{array}$ & $\begin{array}{l}\text { 3.1.4.4.1 } \\
\text { Use of problem } \\
\text { analysis techniques } \\
\text { and engineering } \\
\text { tools to reach the } \\
\text { solution }\end{array}$ & $\begin{array}{l}\text { Does not correctly } \\
\text { develop the selected } \\
\text { concept. }\end{array}$ & $\begin{array}{l}\text { Develops fairly well } \\
\text { the selected concept } \\
\text { by appropriately using, } \\
\text { in most cases, } \\
\text { engineering problem } \\
\text { analysis techniques, } \\
\text { engineering tools and } \\
\text { the investigation. }\end{array}$ & $\begin{array}{l}\text { Rigorously develops } \\
\text { the selected concept } \\
\text { by appropriately } \\
\text { using engineering } \\
\text { problem analysis } \\
\text { techniques, } \\
\text { engineering tools } \\
\text { and the } \\
\text { investigation. }\end{array}$ & $\begin{array}{l}\text { Rigorously develops the } \\
\text { selected concept, and } \\
\text { even goes so far as to } \\
\text { optimize the solution, by } \\
\text { wisely using engineering } \\
\text { problem analysis } \\
\text { techniques, engineering } \\
\text { tools and the } \\
\text { investigation. }\end{array}$ \\
\hline $\begin{array}{l}\text { 3.1.4.5 } \\
\text { Assess the } \\
\text { selected } \\
\text { solution }\end{array}$ & $\begin{array}{l}\text { 3.1.4.5.1 } \\
\text { Approach based on } \\
\text { assessment criteria }\end{array}$ & $\begin{array}{l}\text { Assesses in a rational } \\
\text { and objective manner, } \\
\text { but with a certain lack } \\
\text { of rigour, the } \\
\text { performance of the } \\
\text { solution developed, } \\
\text { with minimal } \\
\text { consideration to } \\
\text { specifications. }\end{array}$ & $\begin{array}{l}\text { Assesses in a rational } \\
\text { and objective manner } \\
\text { the performance of the } \\
\text { solution developed by } \\
\text { taking specifications } \\
\text { into account. }\end{array}$ & $\begin{array}{l}\text { Assesses in a } \\
\text { rational and } \\
\text { objective manner } \\
\text { the performance of } \\
\text { the solution } \\
\text { developed. Takes } \\
\text { specifications into } \\
\text { account. }\end{array}$ & $\begin{array}{l}\text { Assesses in a rational } \\
\text { and comprehensive } \\
\text { manner the performance } \\
\text { of the solution developed } \\
\text { by wisely taking } \\
\text { specifications into } \\
\text { account. }\end{array}$ \\
\hline
\end{tabular}

\footnotetext{
${ }^{1}$ Constraints relating to the engineering problem may involve technology, economics, public health and safety, legislation, standards,
} the environmental, culture and society.

CEEA13; Paper 154

Montreal, QC; June 17-20, $2013 \quad-7$ of $7-$ 